\author{
Krystyna KUŹNIAR ${ }^{1}$ \\ Maciej ZAJĄC ${ }^{2}$
}

\title{
ODPOWEDŹ DYNAMICZNA BUDYNKU MIESZKALNEGO PO TERMOMODERNIZACJI NA WSTRZĄSY POCHODZENIA GÓRNICZEGO
}

\begin{abstract}
Budynki prefabrykowane, wzniesione w drugiej połowie dwudziestego wieku, nadal stanowią liczną grupę wśród budynków mieszkalnych w Polsce. W ostatnich latach, w wyniku nowych wymagań dotyczących ochrony środowiska oraz właściwości cieplnych budynków, obiekty te są modernizowane. Wprowadzane zmiany dotyczą głównie izolacyjności cieplnej ścian zewnętrznych. W typowych technologiach zwiększeniu ulega grubość ściany poprzez wprowadzenie dodatkowych warstw styropianu, wełny mineralnej, zbrojonej zaprawy, siatki z włókna szklanego. Termomodernizacja budynku skutkuje zatem zwiększeniem jego masy i może zmienić sztywność konstrukcji. W niniejszej pracy analizowano wpływ wykonanej termomodernizacji prefabrykowanego, wysokiego budynku mieszkalnego zlokalizowanego w obszarze jednego z najbardziej aktywnych sejsmicznie regionów górniczych w Polsce - Legnicko-Głogowskiego Okręgu Miedziowego, na jego odpowiedź dynamiczną na działanie wstrząsów górniczych. W obliczeniach wykorzystano metodę elementów skończonych. Rozważano użycie do modelowania ścian przed i po termomodernizacji modelu wielowarstwowego oraz prostego modelu jednowarstwowego o zastępczych, uśrednionych parametrach. Otrzymane wyniki obliczeń wskazują, że termomodernizacja rozważanego budynku praktycznie nie zmienia wartości częstotliwości drgań własnych tej konstrukcji i odpowiedzi na wymuszenie parasejsmiczne w postaci wstrząsów górniczych.
\end{abstract}

Słowa kluczowe: budynek prefabrykowany, model numeryczny, wstrząsy górnicze, drgania budynku, izolacja cieplna budynku, termomodernizacja

\section{Wprowadzenie}

Budynki prefabrykowane, wzniesione $\mathrm{w}$ drugiej połowie dwudziestego wieku, nadal stanowią bardzo liczną klasę budynków mieszkalnych w Polsce.

W ostatnich latach, w wyniku nowych wymagań (przepisów) dotyczących ochrony środowiska oraz właściwości cieplnych budynków, obiekty te są mo-

${ }^{1}$ Autor do korespondencji: Krystyna Kuźniar, Uniwersytet Pedagogiczny w Krakowie, Instytut Techniki, ul. Podchorążych 2, 30-084 Kraków, tel. 126626339; kkuzniar@up.krakow.pl

${ }^{2}$ Maciej Zając, Uniwersytet Pedagogiczny w Krakowie, Instytut Techniki, ul. Podchorążych 2, 30-084 Kraków, tel. 126626339; mjzajac@up.krakow.pl 
dernizowane. Wprowadzane zmiany dotyczą głównie izolacyjności cieplnej ścian zewnętrznych. W typowych technologiach zwiększeniu ulega grubość ściany poprzez wprowadzenie dodatkowych warstw styropianu, wełny mineralnej, zbrojonej zaprawy, siatki z włókna szklanego. Termomodernizacja budynku skutkuje zatem zwiększeniem jego masy i może zmienić sztywność konstrukcji.

W niniejszej pracy analizowano wpływ wykonanej termomodernizacji prefabrykowanego, wysokiego budynku mieszkalnego zlokalizowanego w obszarze jednego z najbardziej aktywnych sejsmicznie regionów górniczych w Polsce Legnicko-Głogowskiego Okręgu Miedziowego (LGOM), na jego odpowiedź dynamiczną na działanie wstrząsów górniczych. W obliczeniach wykorzystano metodę elementów skończonych. Rozważano użycie do modelowania ścian przed i po termomodernizacji modelu wielowarstwowego oraz prostego modelu jednowarstwowego o zastępczych, uśrednionych parametrach.

\section{Analizowany budynek}

Analizowany budynek jest typowym w LGOM, wysokim (12-kondygnacyjnym), prefabrykowanym (wielkopłytowym) budynkiem mieszkalnym. Składa się z dwóch oddylatowanych części: jedno- i dwuklatkowej. Obie części są podpiwniczone, posadowione na ławach fundamentowych. Obiekt wzniesiono w poprzeczno-podłużnym układzie ścian nośnych. Wysokość kondygnacji wynosi $2,7 \mathrm{~m}$.

Z uwagi na oddziaływania w postaci wstrząsów górniczych, konstrukcja budynku została wzmocniona poprzez wprowadzenie dodatkowych przęseł wykonanych w technologii betonu monolitycznego, przylegających do ścian szczytowych oraz wzmocnienia ścian wewnętrznych w skrajnych segmentach. Wzmocnienie sięga do poziomu 7 i 10 kondygnacji odpowiednio w części jednoklatkowej i dwuklatkowej. Dobudowane części posadowione są na fundamentach płytowych. Na rys. 1 pokazano widok rozważanego budynku, a na rys. 2 schematycznie przedstawiono rzuty poziome segmentów budynku: segmentu typowego i wzmocnionego.

Każda z prefabrykowanych ścian zewnętrznych składa się z trzech warstw: nośnej, izolacji termicznej i warstwy elewacyjnej. W ramach termomodernizacji budynku, wprowadzono kolejne warstwy, które złożone są z warstw styropianu, siatki z włókna szklanego, zaprawy klejowo-szpachlowej. Układ warstw w ścianie prefabrykowanej przed dociepleniem oraz po dołożeniu warstw izolacji cieplnej pokazano na rys. 3, a w tabeli 1 podano grubości i parametry materiałowe poszczególnych warstw. 


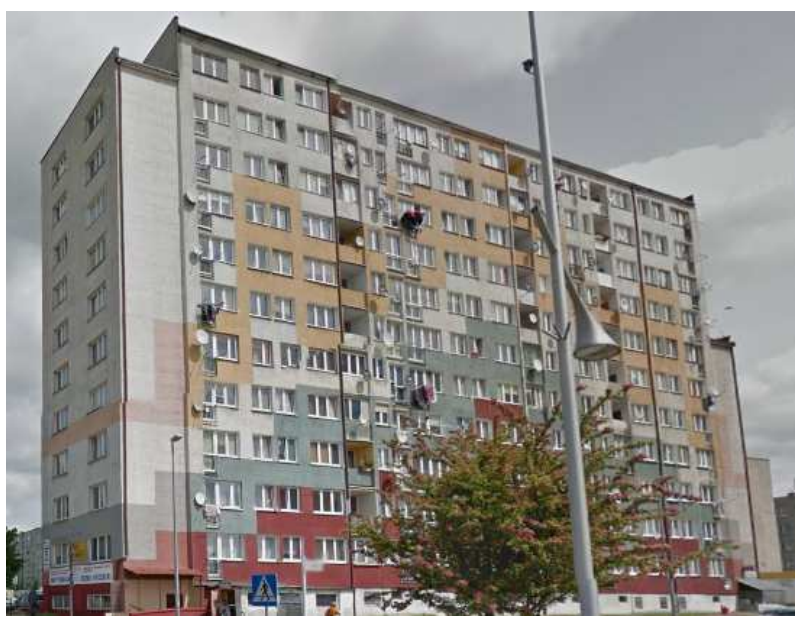

Rys.1. Widok analizowanego budynku

Fig. 1. Analysed building - view

a)

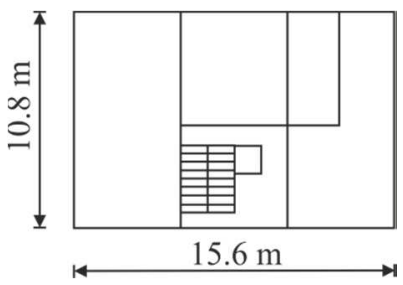

b)

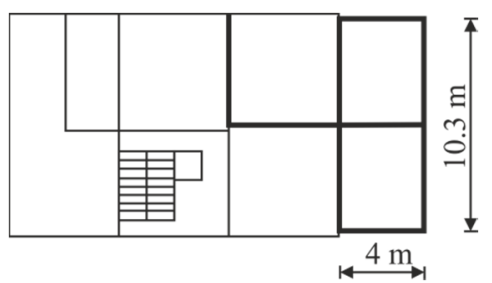

Rys. 2. Segmenty budynku: a) typowy; b) po wzmocnieniu

Fig. 2. Building segments: a) typical; b) after reinforcement

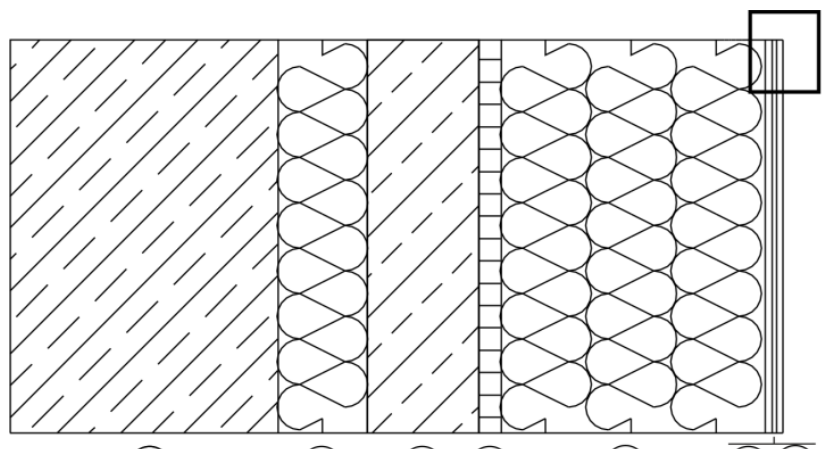

(1)

(2)

(3) (4)

(5)

(6) 8

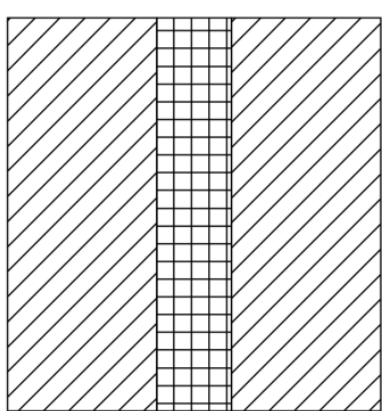

(6) (7) (8)

Rys. 3. Ściana budynku: 1-3 - warstwy ściany prefabrykowanej, 4-8 - warstwy izolacji cieplnej

Fig. 3. Building's wall: 1-3 - layers of prefabricated wall, 4-8 - thermal insulation layers 
Tabela 1. Parametry materiałowe warstw, na podstawie $[1,2,3]$

Table 1. Material parameters of layers, based on $[1,2,3]$

\begin{tabular}{|c|c|c|c|c|}
\hline Nr warstwy & Materiał & Grubość [cm] & $\boldsymbol{E}[\mathbf{G P a}]$ & $\boldsymbol{v}[-]$ \\
\hline 1 & żelbet & 12 & 20 & 0,2 \\
\hline 2 & styropian & 4 & 0,003 & 0,07 \\
\hline 3 & beton fakturowy & 5 & 20 & 0,2 \\
\hline 4 & zaprawa klejowo -szpachlowa & 1 & 20 & 0,2 \\
\hline 5 & styropian & 10 & 0,003 & 0,07 \\
\hline 6 & zaprawa klejowo - szpachlowa & 0,2 & 20 & 0,2 \\
\hline 7 & siatka z włókna szklanego & 0,1 & 66 & 0,23 \\
\hline 8 & zaprawa klejowo - szpachlowa & 0,2 & 20 & 0,2 \\
\hline
\end{tabular}

\section{Model numeryczny}

Model numeryczny budynku (rys. 4) wykonano w programie Ansys z wykorzystaniem 4-węzłowych elementów skończonych typu SHELL o 6 stopniach swobody [4]. Wpływ złączy w ścianach prefabrykowanych na sztywność konstrukcji uwzględniono poprzez redukcję modułu sprężystości elementów konstrukcyjnych. W obliczeniach uwzględniono podatność podłoża oraz przyjęto liniowo-sprężyste modele materiałowe.

Wielowarstwowość ścian zewnętrznych przed i po termomodernizacji modelowano na dwa sposoby z użyciem modelu A i modelu B ściany. W modelu A wykorzystano element wielowarstwowy SHELL181 [4], umożliwiający uwzględnienie w obliczeniach parametrów każdej warstwy z osobna (model dokładny). Natomiast model B jest prostym modelem jednowarstwowym o zastępczych, uśrednionych parametrach - module Younga $\left(E_{\text {eqv }}\right)$ i współczynniku Poissona (v), wyliczanych odpowiednio według wzorów (1) i (2):

$$
\begin{gathered}
E_{\text {eqv }}=\frac{\sum_{i} E_{i} \cdot d_{i}}{\sum_{i} d_{i}} \\
v_{\text {eqv }}=\frac{\sum_{i} v_{i} \cdot d_{i}}{\sum_{i} d_{i}}
\end{gathered}
$$

gdzie: $E_{e q v}, v_{e q v}$ - odpowiednio zastępczy moduł Younga i współczynnik Poissona dla całego modelu,

$E_{i}, v_{i}$ - moduł Younga i współczynnik Poissona poszczególnych, kolejnych warstw,

$d_{i}$ - grubość danej warstwy. 


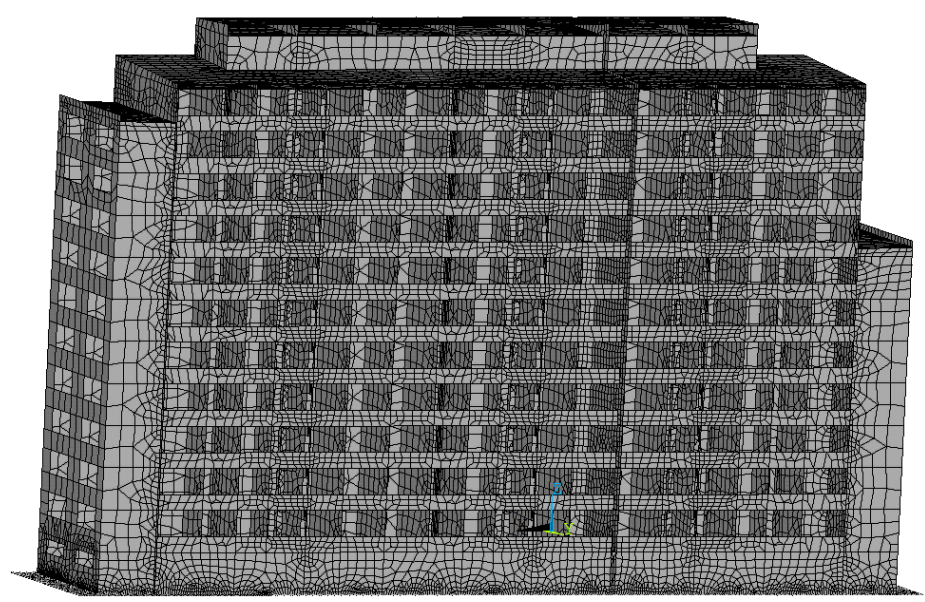

Rys. 4. Model MES analizowanego budynku

Fig. 4. FE model of the analysed building

\section{Analizowane wymuszenia drgań od wstrząsów górniczych}

Źródłem zarejestrowanych wymuszeń kinematycznych (na fundamencie) drgań rozważanego budynku były wstrząsy pochodzenia górniczego, które wystąpiły w LGOM. Do analizy wzięto dwa wstrząsy wysokoenegetyczne o energiach rzędu $10^{8} \mathrm{~J}$. Odległość epicentralna pierwszego z nich wynosiła ponad $2,5 \mathrm{~km}$, a drugiego ok. $700 \mathrm{~m}$. Uwagę skupiono na składowych przebiegów przyśpieszeń drgań w dwóch kierunkach drgań poziomych: x i y, równoległych odpowiednio do osi poprzecznej i podłużnej budynku.

Na rys. 5 pokazano przebiegi wypadkowych poziomych przyśpieszeń drgań wymuszenia 1 i wymuszenia 2 , a na rys. 6 - odpowiednie przyśpieszeniowe spektra odpowiedzi od drgań składowych. Widać, że w wymuszeniu 1 dominują stosunkowo niskie częstotliwości, natomiast w wymuszeniu 2 zauważyć można dwa pasma dominujących częstotliwości.

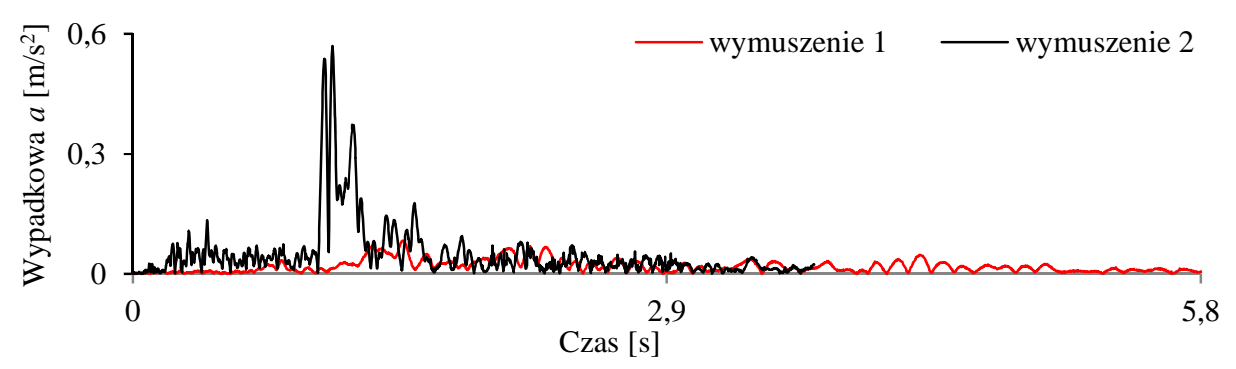

Rys. 5. Przebiegi wypadkowych poziomych przyśpieszeń drgań - wymuszenia

Fig. 5. Records of resultant acceleration of horizontal vibrations - excitations 
a)

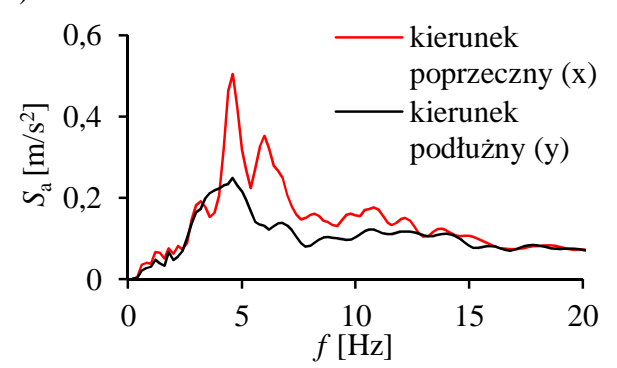

b)

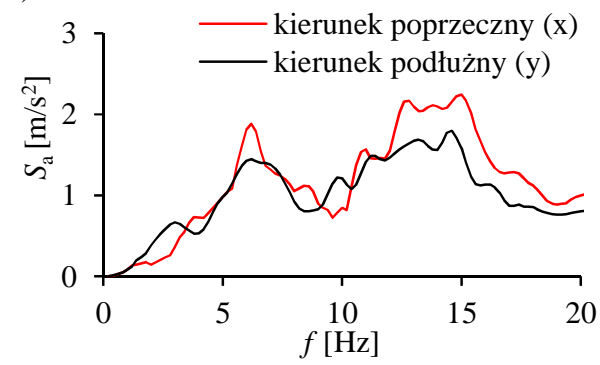

Rys. 6. Przyśpieszeniowe spektra odpowiedzi $S_{a}$ : a) wymuszenie 1 , b) wymuszenie 2

Fig. 6. Acceleration response spectra $S_{a}$ : a) excitation 1, b) excitation 2

\section{Wyniki obliczeń}

W tabeli 2 porównano obliczone i wyznaczone doświadczalnie częstotliwości poziomych drgań własnych budynku przed i po termomodernizacji. Z kolei na rys. 7 - rys. 10 porównano wybrane przebiegi przyśpieszeń poziomych drgań składowych (kier. x, kier. y) budynku przed i po termomodernizacji, wyznaczone $\mathrm{z}$ użyciem modelu A oraz modelu B.

Mimo zwiększenia masy obiektu na skutek wprowadzenia dodatkowych warstw termomodernizacyjnych, wartości częstotliwości drgań własnych budynku i jego odpowiedzi dynamiczne na oddziaływania paraseismiczne (wstrząsy górnicze) praktycznie nie różnią się od tych wyznaczonych dla budynku przed termomodernizacją. Pewnym wyjaśnieniem tego efektu może być fakt, że dokładane $\mathrm{w}$ procesie termomodernizacji budynku elementy niekonstrukcyjne poza tym, że stanowią „,balast” dla konstrukcji, mogą też istotnie wpływać na zwiększenie sztywności obiektów i dalej na ich charakterystyki dynamiczne [7, 8].

Tabela 2. Porównanie obliczonych i wyznaczonych doświadczalnie częstotliwości poziomych drgań własnych budynku przed i po termomodernizacji

Table 2. Comparison of the computed and experimental values of natural frequencies of horizontal vibrations of the building before and after thermo-modernization

\begin{tabular}{|c|c|c|c|c|c|c|}
\hline \multirow{4}{*}{$\begin{array}{l}\text { Kierunek } \\
\text { drgań }\end{array}$} & \multicolumn{6}{|c|}{ Częstotliwość poziomych drgań własnych budynku $f[\mathrm{~Hz}]$} \\
\hline & \multicolumn{3}{|c|}{ Przed termomodernizacją } & \multicolumn{3}{|c|}{ Po termomodernizacji } \\
\hline & \multirow{2}{*}{$\begin{array}{c}\mathrm{Z} \text { pomiarów } \\
{[5,6]}\end{array}$} & \multicolumn{2}{|c|}{ Obliczone } & \multirow{2}{*}{ Z pomiarów } & \multicolumn{2}{|c|}{ Obliczone } \\
\hline & & model A & model B & & model A & model B \\
\hline Poprzeczny $(\mathrm{x})$ & $1,56-1,71$ & 1,80 & 1,82 & $1,50-1,64$ & 1,80 & 1,82 \\
\hline Podłużny (y) & $2,06-2,28$ & 2,49 & 2,52 & $2,08-2,27$ & 2,49 & 2,53 \\
\hline
\end{tabular}

Różnice w wartościach częstotliwości drgań własnych rozważanego budynku obliczonych z użyciem modelu wielowarstwowego A i jednowarstwowego 
modelu B (tabela 2), zarówno w przypadku budynku przed termomodernizacją, jak i po zwiększeniu izolacyjności cieplnej ścian zewnętrznych, są nieznaczne.

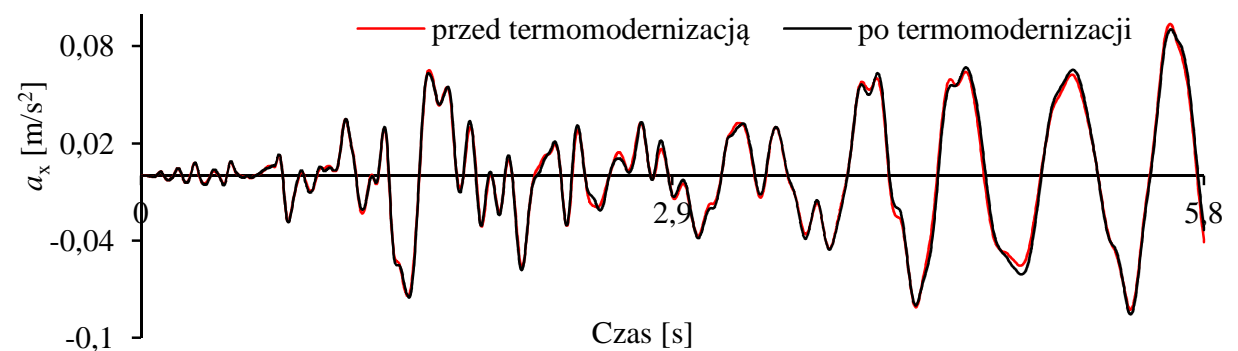

Rys. 7. Porównanie przebiegów przyśpieszeń poziomych drgań budynku w kierunku poprzecznym (x) przed i po termomodernizacji - wymuszenie 1, model A

Fig. 7. Comparison of records of horizontal accelerations of building vibrations in transverse direction (x) before and after thermo-modernization - excitation 1, model A

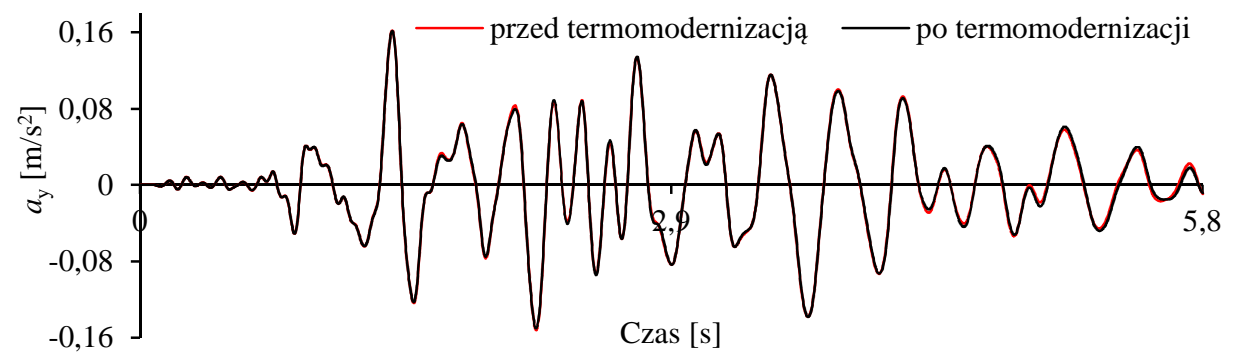

Rys. 8. Porównanie przebiegów przyśpieszeń poziomych drgań budynku w kierunku podłużnym (y) przed i po termomodernizacji - wymuszenie 1 , model A

Fig. 8. Comparison of records of horizontal accelerations of building vibrations in longitudinal direction (y) before and after thermo-modernization - excitation 1, model A

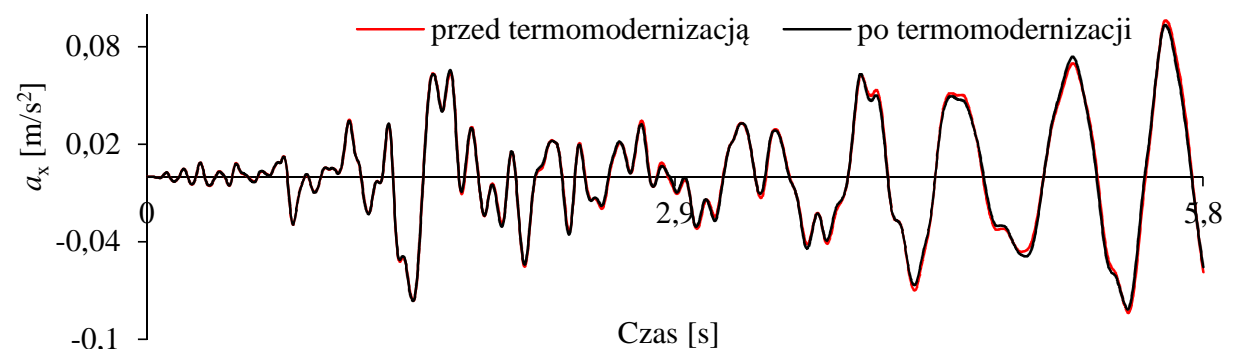

Rys. 9. Porównanie przebiegów przyśpieszeń poziomych drgań budynku w kierunku poprzecznym (x) przed i po termomodernizacji - wymuszenie 1, model B

Fig. 9. Comparison of records of horizontal accelerations of building vibrations in transverse direction $(\mathrm{x})$ before and after thermo-modernization - excitation 1, model $\mathrm{B}$ 


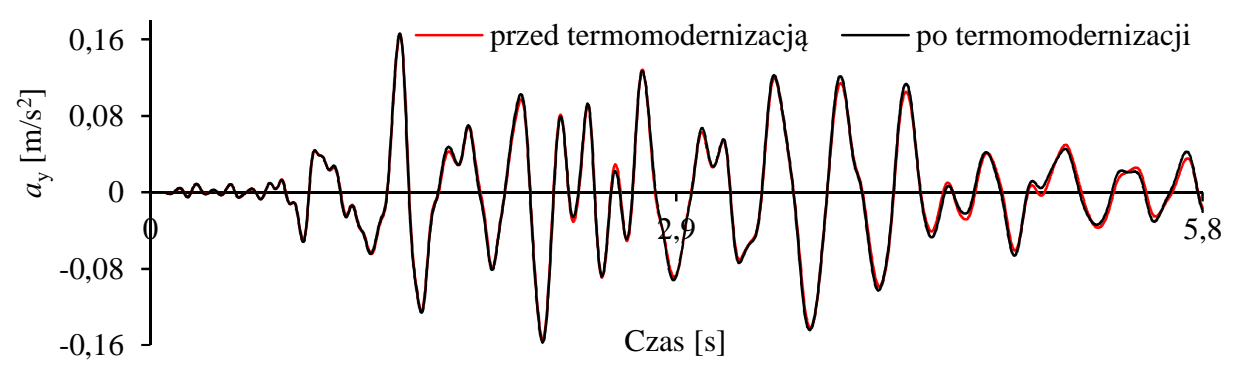

Rys. 10. Porównanie przebiegów przyśpieszeń poziomych drgań budynku w kierunku podłużnym (y) przed i po termomodernizacji - wymuszenie 1, model B

Fig. 10. Comparison of records of horizontal accelerations of building vibrations in longitudinal direction (y) before and after thermo-modernization - excitation 1, model B

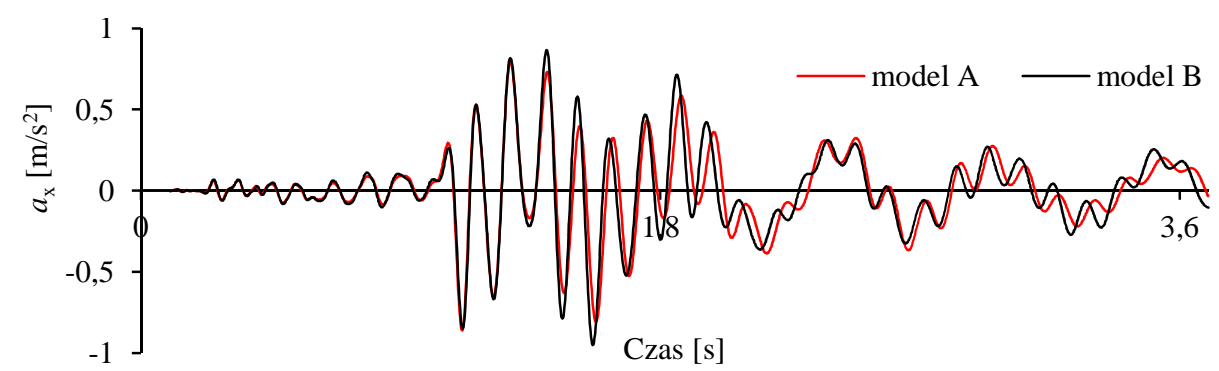

Rys. 11. Porównanie przebiegów przyspieszeń poziomych drgań budynku w kierunku poprzecznym (x) wyznaczonych z użyciem modeli A i B budynku przed termomodernizacją, wymuszenie 2

Fig. 11. Comparison of records of horizontal accelerations of vibrations in transverse direction (x) determined using $\mathrm{A}$ and $\mathrm{B}$ models of the building before thermo-modernization, excitation 2

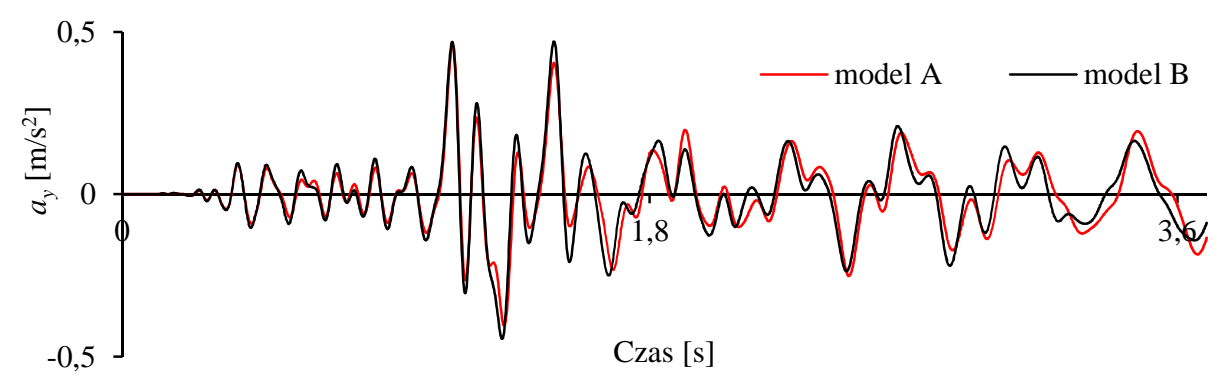

Rys. 12. Porównanie przebiegów przyspieszeń poziomych drgań budynku w kierunku podłużnym (y) wyznaczonych z użyciem modeli A i B budynku po termomodernizacji, wymuszenie 2

Fig. 12. Comparison of records of horizontal accelerations of vibrations in longitudinal direction (y) determined using A and B models of the building after thermo-modernization, excitation 2 
Również za pomijalnie małe w praktyce można uznać różnice w wyznaczonych numerycznie $\mathrm{z}$ wykorzystaniem modeli A i B odpowiedziach budynku przed i po termomodernizacji na wymuszenia generowane wstrząsami górniczymi, co przykładowo ilustrują rys. 11 i rys. 12 .

\section{Uwagi końcowe}

Otrzymane wyniki obliczeń wskazują, że termomodernizacja rozważanego prefabrykowanego, wysokiego budynku mieszkalnego praktycznie nie zmienia wartości częstotliwości poziomych drgań własnych tej konstrukcji oraz jej odpowiedzi dynamicznej na wymuszenie parasejsmiczne w postaci wstrząsów górniczych.

Stwierdzono ponadto, że zastosowanie w obliczeniach bardzo prostego modelu ściany o zastępczych parametrach (moduł Younga i ułamek Poissona) prowadzi do wyników bardzo bliskich uzyskanym z użyciem modelu wielowarstwowego, a pozwala na redukcję wysiłku numerycznego. Zatem taki prosty model można byłoby rekomendować do obliczeń dotyczących tak dużych konstrukcji, o bardzo dużej liczbie stopni swobody, jakimi są prefabrykowane budynki mieszkalne.

Obliczenia do pracy wykonano z wykorzystaniem Infrastruktury PLGrid.

\section{Literatura}

[1] Dzierżewicz Z., Starosolski W.: Systemy budownictwa wielkopłytowego w Polsce w latach 1970-1985, Wolters Kluwer Polska, Warszawa 2010.

[2] Bathurst R. J., Zarnani S., Gaskinszósty A.: Shaking table testing of geofoam seismic buffers, Soil Dynamics and Earthquake Engineering, Elsevier, 27(4), 2007, s. 324-332.

[3] Hartman D., Greenwood M. E., Miller D. M.: High Strength Glass Fibres, AGY Technical Paper, USA, 2006.

[4] Release 11.0 Documentation for Ansys 2007.

[5] Maciąg E., Kowalski W.: Ocena zmian cech dynamicznych budynków podlegających działaniom wstrząsów górniczych, ZN Politechniki Rzeszowskiej, Mechanika, 60, 2002, s. 405-414.

[6] Kowalski W.: Wyznaczanie sił sejsmicznych w budynkach podlegającym wstrząsom górniczym, Rozprawa doktorska, Politechnika Krakowska, 1997.

[7] Maciąg E., Kuźniar K.: Wpływ elementów niekonstrukcyjnych na częstotliwości drgań własnych ścianowych budynków prefabrykowanych, Inżynieria i Budownictwo, nr 10, 1993, s. 423-425.

[8] Kowalska A.: Analiza wpływu elementów niekonstrukcyjnych na charakterystyki dynamiczne budynków, Rozprawa doktorska, Politechnika Krakowska, 2007. 


\section{DYNAMIC RESPONSE OF APARTMENT BUILDING AFTER THERMO-MODERNIZATION ON MINE-INDUCED ROCKBURSTS}

\section{S u m m a r y}

Prefabricated buildings erected in the second half of the twentieth century still constitute a large group of apartment buildings in Poland. Nowadays, as a result of new environmental regulations as well as the necessity to improve energy properties they are modernized. These changes mainly concern thermal insulation of external walls. Application of typical technologies results in increasing of the walls thickness by adding the extra layers of styrofoam, rock or mineral wool, reinforced mortar, glass fibre textile mesh. Therefore such thermo-modernization causes increasing of the building mass and can change the stiffness of structure.

In this paper the influence of the performed thermo-modernization of the prefabricated, highrise, apartment building located in the area of the one of the most seismically active mining region in Poland - Legnica-Glogow Copperfield, on the mine-induced building dynamic response. $\mathrm{Nu}-$ merical calculations were carried out using finite element method software. A multi-layer model as well as simple one layer model with equivalent parameters were taken into consideration for modelling the walls before and after thermo-modernization. The results of calculations indicate that the thermo-modernization of the considered building practically does not change the values of frequencies of natural vibrations and the dynamic response on the mine-induced excitations of the structure.

Keywords: prefabricated building, numerical model, mining tremors, building vibrations, building thermal insulation, thermo-modernization

Przestano do redakcji: 28.02 .2017 r.

Przyjęto do druku: 28.04.2017 r. 